\title{
TRANSPLANTE RENAL NO BRASIL: PROBLEMAS E POSSÍVEIS SOLUÇÕES
}

\author{
Renal transplant in Brazil: issues and possible solutions
}

Luiz Estevam lanhez

\begin{abstract}
Institulção
Departamento de Nefrologia dos Hospitais:

Alemão Oswaldo Cruz, Bandeirantes e Beneficência Portuguesa de São Paulo

São Paulo/SP

\section{Correspondência:}

Luiz Estevam lanhez

Endereço: Rua Treze de Maio, 1856 - Cj. 91 - CEP 01327-002 São Paulo - SP

Telefone: (11) 3251.3034

E-mail: leianhez@uol.com.br
\end{abstract}

Recebido em: 08/03/17

Aceito em: 30/03/17

Com a experiência cirúrgica, a escolha adequada do doador vivo ou falecido e o surgimento de novas drogas imunossupressoras nos últimos quinze anos, a sobrevida do paciente e a do enxerto está excelente acima de $95 \%$ nos primeiros anos.

A grande dificuldade é a falta de doadores, problema este presente na maioria dos países; a aceitação de doador vivo parente ou não parente, quando bem avaliada é a melhor opção, pois proporciona melhor sobrevida para o paciente e enxerto em longo prazo. No meu ponto de vista, ser contrário a esse procedimento não é aceitável.

Quanto à falta de doador falecido tanto no Brasil como em outros países, existe essa carência e não há solução adequada.

Nos últimos anos, no Brasil o número de doadores falecidos está em aproximadamente $80 \%$, sendo que essa percentagem representa o número de doadores vivos no ano de 2005, o que significa ter havido inversão do tipo de doador.

No ano de 2015, de acordo com os dados da Associação Brasileira de Transplantes de Órgãos - ABTO, houve 5.579 transplantes renais, sendo que $88 \%$ deles foram realizados em apenas oito Estados, assim mostrados em ordem decrescente, quais sejam: São Paulo, Rio Grande do Sul, Minas Gerais, Paraná, Rio de Janeiro, Pernambuco, Ceará e Santa Catarina, sendo que os outros estados e o Distrito Federal realizaram apenas $12 \%$; embora considerando a menor população, a percentagem é significativa. Nota-se que quatro desses estados não tiveram nenhuma atividade de transplante. O número de pacientes em lista de espera de doador falecido nem sempre é proporcional ao número de transplantes realizados por estado; assim, no ano de 2016, em São Paulo havia 10.030 pacientes, Minas Gerais 2.312, Espírito Santo 960, Rio Grande do Sul 841, Bahia 699 e Distrito Federal 234. Por outro lado, havia estados que não possuíam nenhum paciente na lista, como por exemplo, Mato Grosso e Sergipe.

Como a lista de receptores de rim de doador falecido não funciona nos estados que não realizam quantidade suficiente de transplantes, esses pacientes vão a óbito enquanto estão em diálise ou então, procuram outros estados, principalmente, São Paulo.

Para solucionar essa falta de transplante nos estados que não realizam transplante, o Governo local fornece o chamado "Tratamento Fora do Domicílio (TFD)", incluindo passagem área e ajuda de custo para o paciente e acompanhante, mas somente para aqueles que possuem doador vivo.

Os pacientes que residem em locais distantes e que não têm tempo hábil para chegar ao centro transplantador, como por exemplo, aqueles que residem nos estados 
do Mato Grosso ou de Roraima, não têm condições para inscrever-se na lista de espera de doador falecido. Assim sendo, enquanto se preparam para o transplante, alguns deles passam a residir temporariamente em São Paulo, em domicílio de parente, hotéis baratos ou em casa de apoio oferecida pelo centro transplantador.

Com a finalidade de solucionar essa carência nos estados distantes, o grupo HEPATO criou centros de transplantes de órgãos em locais necessitados, chamando o programa de "Transplantes Sem Fronteiras". Esse grupo cria serviços de transplantes associando-se a profissionais locais, e seus profissionais deslocam-se para realizar as cirurgias, além de auxiliar no seguimento pós-operatório. Foi criado esse tipo de serviço de transplante de rim e fígado nas cidades de Rio Branco - AC, Belém - PA, Goiânia - GO, Itabuna - BA, Redenção - PA e Brasília $D F$, programa esse que deveria ser adotado pelos outros estados onde não são realizados transplantes.

No seguimento pós-transplante, em muitos estados há profissionais treinados para realizar o acompanhamento; entretanto, muitos deles recusam esse tipo de trabalho, o que traz problemas sérios para os pacientes, uma vez que precisam locomover-se com frequência para São Paulo, quase sempre com TFD e, o mais grave, o governo estadual local não fornece os medicamentos imunossupressores de alto custo. Então, o governo do estado de São Paulo acaba fornecendo mesmo para aqueles pacientes que residem fora de São Paulo.

Esses problemas poderiam ser solucionados com vontade política, incentivo tanto aos profissionais como aos hospitais locais, melhor distribuição e organização de centros de transplante, visto que o provedor desses procedimentos, em sua grande maioria, é o próprio SUS, que realiza desde estudo pré-transplante até a manutenção do transplante.

Os centros de transplante deveriam obrigatoriamente realizar um número anual de cirurgias, de acordo com a população e o número de pacientes em lista de espera, com a finalidade de diminuir o sofrimento desses pacientes e dos seus familiares quando procuram $o$ tratamento fora do munícipio.
O Brasil realiza grande número de transplantes de rim, principalmente em São Paulo, porém, na minha experiência, a reabilitação dos pacientes transplantados pelo SUS deixa a desejar.

Em 1997, na pesquisa realizada na Unidade de Transplante Renal do Hospital das Clínicas e na clínica privada foi criado um questionário preenchido voluntariamente pelos pacientes, avaliando suas condições socioeconômicas e educacionais, sendo que 84 deles eram de clínica privada (grupo I) e 87 do Hospital das Clínicas (grupo II). Todos os pacientes transplantados estavam em perfeitas condições de saúde física e mental.

As idades era iguais: 43 anos no Grupo I e 46 anos no Grupo II, e também eram iguais o sexo e estado civil.

Em relação ao número de pacientes que não trabalhavam ou trabalhavam e eram aposentados, no Grupo I eram $18 \%$ e no Grupo II, $55 \%$. No grupo I, o trabalho normal foi de $90 \%$, enquanto que no Grupo II, somente $58 \%$, significando que $18 \%$ dos pacientes do Grupo I estavam aposentados, a maioria deles por tempo de serviço, contra $55 \%$ do Grupo II, que tinha a minoria por tempo de serviço.

Conclui-se que, apesar do transplante ser bem sucedido, apenas $30 \%$ dos pacientes do SUS conseguiam exercer atividade profissional normalmente, contra $81 \%$ da clínica privada.

Os dados atuais também mostram a baixa reabilitação dos pacientes do SUS, conforme pesquisa realizada pela Enfermagem do Serviço de Transplante do Hospital Bandeirantes. Essa situação torna-se preocupante, uma vez que o SUS tem alto custo financeiro com esses procedimentos e baixa percentagem de reabilitação, o que poderia ser solucionado se fossem criadas condições para recolocá-los no mercado de trabalho, como ocorre com trabalhadores portadores de deficiência física.

Temos ainda muitos desafios para transplantar todos os pacientes que necessitam, mas não podemos empregar tantos recursos e não conseguir a reabilitação desses pacientes transplantados para o trabalho normal 